\title{
Post-Pleistocene diachronic change in East Asian facial skeletons: the size, shape and volume of the orbits
}

\author{
PETER BROWN ${ }^{1,2 *}$, TOMOKO MAEDA ${ }^{1}$ \\ Department of Anatomy and Anthropology, Tohoku University School of Medicine, Sendai, Japan, ${ }^{2}$ \\ Palaeoanthropology, School of Human \& Environmental Studies, University of New England, Armidale, NSW 2351, Australia ${ }^{2}$
}

Received 14 April 2003; accepted 18 July 2003

\begin{abstract}
Globally there was a reduction in the size and robusticity of the human orofacial skeleton and dentition after the Pleistocene. There was also diachronic change in brain size and skeletal mass in general. Anthropologists have developed numerous models in explanation of the evolutionary process, with the majority linked to the cultural developments of the Neolithic. These cultural models are challenged by the skeletal evidence from societies with contrasting culture histories. In China there is a reduction in facial breadth, height and prognathism, posterior tooth size, brain volume and cranial robusticity from the Neolithic to the modern period. However, the height of the orbits increases rather than decreases. Examination of the structural relationships between orbit and facial dimensions in Tohoku Japanese and Australian Aboriginal crania suggests a steady reduction in orbit volume in China. This may have resulted in a more anterior placement of the eyeball and associated structures in modern East Asians than in their Neolithic counterparts.
\end{abstract}

Key words: Post-Pleistocene, Neolithic, China, human facial skeleton, orbit

\section{Introduction}

For our own species there is now a considerable body of data describing an apparently global trend for directional reduction in body mass, skeletal size and robusticity, and tooth size in the post-Pleistocene period. Preservation and a greater understanding of the genetic and phenotypic contributions to tooth size has resulted in a concentration on dental metrics, with claims for dental reduction in Europe (Frayer, 1978; Formicola, 1987; y'Edynak, 1989), South and East Asia (Brace et al., 1984; Kennedy, 1984; Lukacs, 1984), Eastern Mediterranean, Africa and the Levant (Le Blanc and Black, 1974; Calcagno, 1986; Smith et al., 1986), Mexico (Christensen, 1998) and Australia (Brown, 1992a). Importantly, however, where the oro-facial skeleton, cranial vault and other parts of the skeleton are also present it appears that there has been a significant reduction in the entire masticatory system, brain volume, and skeletal mass in general (Carlson, 1976; Carlson and Van Gervan, 1977; Smith et al., 1984, 1985, 1986; Brown, 1987, 1992b; Henneberg and Steyn, 1993).

While there is general agreement as to the presence of this diachronic trend, there is considerable debate as to the evolutionary mechanism involved. In part this reflects a concentration of many researchers on a single aspect of our skeletal, or dental, system rather than considering the organism as a whole. The majority of anthropologists have argued for

\footnotetext{
* Corresponding author. e-mail: Peter.Brown@metz.une.edu.au Published online 16 April 2004

in J-STAGE (www.jstage.jst.go.jp) DOI: 10.1537/ase.00072
}

some connection between cultural development and the observed changes in phenotype. This is particularly true for the masticatory system, where the focus has been on the relaxation of selection for large tooth size associated with the cooking of food (Brace and Mahler, 1971; Le Blanc and Black, 1974; Carlson and Van Gervan, 1977; y'Edynak, 1978; Calcagno, 1986; Calcagno and Gibson, 1988; Jacobs, 1994). Others have argued that the diachronic trend in human dental proportions is secondary to a change in body size (Sofaer et al., 1971; Sofaer, 1973), with either a reduction in the developmental areas available for teeth, or some allometric scaling effect.

One of the more intriguing aspects of the evidence for post-Pleistocene change is that at a global level there are similar alterations in craniofacial proportions, and these events occur over the same time period. As cultural developments do not have similar levels of global coordination, this provides both a test, and a challenge, for cultural explanations of the evolutionary process (Brown, 1992b). While research has focused on the diachronic trend for tooth size, and to a lesser degree body size, there are associated changes in the facial skeleton which are both unexpected and unexplained. In Australia (Brown, 1992b), North Africa (Calcagno, 1986; Calcagno and Gibson, 1988) and East Asia (Brown, 1992b) reducing facial height and prognathism is accompanied by a relative and absolute increase in orbit height and a decrease in orbit breadth. The functional implications of these changes in orbit dimensions have not previously been explored. This paper will consider diachronic change in the size, shape and volume of the orbits in the context of the post-Pleistocene period in China. The fragile and often incomplete preservation of the posterior orbital plate in 
the Chinese Neolithic samples prevented the direct measurement of orbital volume in these crania. Therefore, the structural associations between orbit volume, and other aspects of orbit size and shape, are first examined in two skeletally contrasting modern human populations; Australian Aborigines and Tohoku Japanese. These two groups were selected as the differences in their average facial proportions parallel those between early Neolithic and modern populations in China. The Australians having size and shape relationships which are similar to generalized early Neolithic populations.

\section{Materials and Methods}

\section{Materials}

Evidence of diachronic change in China was provided by an extended sequence of Neolithic crania, predominantly Yangshao and Lungshan, dating to between 7000 and 2000 years BP, and a comparative northern Chinese modern sample (Table 1). These crania are in the collections of the Institute of Archaeology, Chinese Academy of Social Science, and the Institute of Vertebrate Paleontology and Paleoanthropology, Academia Sinica, Bejing. Observations on all of these were recorded by $\mathrm{PB}$. In order to maximize sample sizes and facilitate examination of diachronic change, the skeletons from these sites were grouped into 1000 year intervals. These raw data are available at Brown (1998-2003).

Examination of the relationship between dimensions of the orbits and orofacial skeleton was made through a comparison of Australian Aboriginal and Tohoku Japanese crania. These two groups were chosen due to their contrasting orbit dimensions, craniofacial proportions and tooth size. The Australian Aboriginal crania, 19 male and 16 female, are in the collection of the Natural History Museum, London. These crania were collected between 1890 and 1930, mainly from south-eastern Australia. Selected crania were primarily from young adults, without extensive tooth loss and alveolar resorption due to acute tooth wear. Sex was determined through an examination of cranial morphology, and the use of discriminant function analysis, as described in Brown (1989).

The Tohoku Japanese crania, 27 males and 17 females, were of known sex and age and form part of the collection in the Department of Anatomy and Anthropology, Tohoku University Medical School. The Tohoku modern collection contains approximately 200 crania, which were collected between 1900 and 1942, along with records giving for each individual the place and date of birth, as well as date and cause of death. Most of them were born in the Tohoku district of northern Japan. An additional 20 crania from this collection were used to test the accuracy of regression equations.

\section{Methods}

Standard osteometric instruments and measurements were used to record dimensions of the cranial vault and orofacial skeleton. These follow the descriptions in Brown (1989), with the majority drawn from Martin and Saller (1957). Orbital breadth and height follow the procedures in Bass (1971, page 69). Procedures were devised for measuring the volume of the orbit, and the area of the orbital aperture as defined by its margins. Where preservation allowed, these were recorded from the right orbit, as were orbital height and breadth.

Orbit volume was measured with mustard seed. The lacrimal duct, orbital fissures, and infraorbital duct (if open) were first covered with thin mending tape, and the optic foramen filled with a standardized piece of cotton wool. The orbit was then filled with mustard seeds level with the orbital margins, represented by a line at which the walls of the orbit meet the anterior aspect of the bone forming the rim (Schultz, 1940). Mustard seed volume was measured to the nearest $0.5 \mathrm{ml}$ with a standard volumetric cylinder, and then this measurement procedure was repeated. If the difference between the two trials did not exceed $0.5 \mathrm{ml}$, the first measurement was accepted; otherwise the average of the two trials was used. This decision was based on the results of the observer error trial described below.

Orbit area was measured from standardized digital photographs of the right orbit. A $100 \mathrm{~mm}^{2}$ scale, suspended on strands of thread, was placed in the middle of the orbit, level with the inferior and superior orbital margins. A high resolution digital photograph was taken of the orbit and transferred to a computer. The image was opened with Adobe Illustrator 9 software (Adobe Systems Incorporated) and the outline of the orbital margin, and $100 \mathrm{~mm}^{2}$ scale, traced with the bezier curve pen tool. The background image of the orbit was then deleted, and the area of the orbit and scale measured with Scion Image 4 software (Scion Corporation). The area of the scale was used to correct the area of the orbit for photographic enlargement, and the life size area calculated.

Prior to significance testing all data were examined for distributional normality and the presence of outliers, using

Table 1. The Neolithic and modern Chinese male samples

\begin{tabular}{|c|c|c|c|c|c|}
\hline Location & $\mathrm{N}$ & \multicolumn{2}{|c|}{ Date range } & Dating methods & References \\
\hline Baoji, Huaxian & 21 & $>5,500$ & $<6,500$ & ${ }^{14} \mathrm{C}$ charcoal and wood & $1,2,3$ \\
\hline $\begin{array}{l}\text { Hejiawan, Xixiahou, Changzhi, Dawenkou, } \\
\text { Hemudu, Jiangzhai }\end{array}$ & 15 & $>4,500$ & $<5,500$ & ${ }^{14} \mathrm{C}$ charcoal, wood, and bone & $1,4,6$ \\
\hline Miaodigou, Wangying & 29 & $>3,500$ & $<4,500$ & ${ }^{14} \mathrm{C}$ charcoal, wood, and bone & 1,5 \\
\hline $\begin{array}{l}\text { Xiaxihe, Xiawanggang, Yingxu, } \\
\text { Yanbulaka, Xunhua, Yangshan }\end{array}$ & 77 & $>2,500$ & $<3,500$ & ${ }^{14} \mathrm{C}$ charcoal and wood & $1,7,8$ \\
\hline Modern north China & 37 & & & & 9 \\
\hline
\end{tabular}

Details of the samples and radiocarbon dating of each of the Neolithic localities can be found in 1: The Institute of Archaeology (1991), 2: Yan et al. (1960), 3: Yan (1962), 4: Yan (1972, 1973), 5: Han and Pan (1979), 6: Han and Pan (1983), 7: Han (1990), 8: Wu and Zhang (1985), 9: Black (1928). 
normal probability plots, stem and leaf plots, and the Shapiro-Wilk statistic (Brown, 1989). Two of the Tohoku Japanese "females" were extreme outliers in terms of their shape and size characteristics. As there was some doubt as to the accuracy of their documented age and sex they were excluded from the analysis. Where a significant difference in group variance was indicated by Levene's F-test, t-tests were calculated using separate variance estimates. The pattern of association between variables was examined using Pearson's correlation coefficient, scatter plots, single and multiple regressions, and plots of residuals. Statistical calculations were performed using SYSTAT 10 (Systat, 2002) and SPSS 11 (SPSS, 1990).

\section{Observer error}

Orbit volume and area were recorded on 20 of the Tohoku Japanese crania on two different occasions, separated by seven days. These were blind trials with the entire procedures repeated. Results were compared using paired t-tests and Pearson's correlation coefficient (Table 2). Recording orbit volume and area involved some measurement error; however, the differences between the trial means were small and insignificant, and the two sets of results highly correlated. Measurement errors of $\pm 19.04 \mathrm{~mm}^{2}$ for orbit area, and $\pm 0.35 \mathrm{ml}$ for orbit volume, were considered acceptable given the scale of the original measurements, and the magnitude of the population differences discussed below.

\section{Results}

\section{Diachronic change in China}

Table 3 shows summary statistics for the Chinese Neolithic and recent samples, with Figure 1 displaying box plots of the distributions of some additional indicators of cranial size, robusticity and tooth size. Average facial proportions, in lateral view, for early Neolithic and modern Chinese males are compared in Figure 2.

From the early Neolithic to the recent period there is a trend towards reducing endocranial volume and cranial

Table 2. Observer error in 20 blind repeats of orbital area and orbital volume measurements with Tohoku Japanese crania

\begin{tabular}{lcccccc}
\hline $\mathrm{N}=20$ & $\begin{array}{c}\text { Area } \\
\text { trial 1 }\end{array}$ & $\begin{array}{c}\text { Area } \\
\text { trial 2 }\end{array}$ & $\begin{array}{c}\text { Volume } \\
\text { trial 1 }\end{array}$ & $\begin{array}{c}\text { Volume } \\
\text { trial 2 }\end{array}$ & $\begin{array}{c}\text { Area } \\
\text { difference }\end{array}$ & $\begin{array}{c}\text { Volume } \\
\text { difference }\end{array}$ \\
\hline $\begin{array}{l}\text { mean } \\
\text { s.d. }\end{array}$ & 1157.6 & 1158.3 & 23.8 & 24.1 & 31.5 & 0.60 \\
\hline \hline & 103.62 & 112.64 & 2.67 & 2.57 & 19.04 & 0.35 \\
\hline $\begin{array}{l}\text { Mean difference } \\
\text { Area trials }\end{array}$ & s.d. difference & $\mathrm{t}$ & $P$ & $\mathrm{r}$ & $P$ \\
$\begin{array}{l}\text { 31.5 } \\
\text { Volume trials } \\
0.60\end{array}$ & 19.04 & -0.082 & 0.936 & 0.94 & 0.000 \\
\hline
\end{tabular}

Descriptive statistics, paired t-test, and Pearson's correlation coefficient.

Table 3. Descriptive statistics and significance tests for the Chinese Neolithic and modern male facial dimensions

\begin{tabular}{|c|c|c|c|c|c|c|c|c|c|}
\hline Dimension & & Samples & $\mathrm{N}$ & Mean & s.d. & F (sample pairs) & $P$ & t (sample pairs) & $P$ \\
\hline \multirow[t]{5}{*}{ Basion-nasion } & 1 & $6.5-5.5 \mathrm{kyr}$ & 12 & 106.5 & 3.52 & $(1-2) 4.14$ & .055 & $(1-2) 0.82$ & .421 \\
\hline & 2 & $5.5-4.5 \mathrm{kyr}$ & 11 & 104.5 & 7.39 & $(2-3) 2.78$ & .107 & $(2-3)-0.02$ & .985 \\
\hline & 3 & $4.5-3.5 \mathrm{kyr}$ & 17 & 104.6 & 4.47 & $(3-4) 0.65$ & .423 & $(3-4) 2.25$ & .027 \\
\hline & 4 & $3.5-2.5 \mathrm{kyr}$ & 69 & 102.2 & 3.66 & (4-5) 0.05 & .824 & (4-5) 3.80 & .000 \\
\hline & 5 & Modern & 37 & 102.1 & 4.84 & $(1-5) 0.06$ & .799 & $(1-5)-5.67$ & .000 \\
\hline \multirow[t]{5}{*}{ Basion-prosthion } & 1 & $6.5-5.5 \mathrm{kyr}$ & 11 & 105.3 & 5.78 & $(1-2) 0.00$ & .991 & $(1-2) 0.73$ & .472 \\
\hline & 2 & $5.5-4.5 \mathrm{kyr}$ & 11 & 103.5 & 5.26 & $(2-3) 0.09$ & .766 & $(2-3) 2.61$ & .015 \\
\hline & 3 & $4.5-3.5 \mathrm{kyr}$ & 16 & 98.4 & 4.81 & $(3-4) 0.42$ & .518 & $(3-4)-0.90$ & .371 \\
\hline & 4 & $3.5-2.5 \mathrm{kyr}$ & 54 & 99.6 & 4.59 & (4-5) 0.90 & .765 & $(4-5) 4.91$ & .000 \\
\hline & 5 & Modern & 35 & 94.9 & 4.05 & $(1-5) 1.23$ & .272 & $(1-5)-6.63$ & .000 \\
\hline Maximum & 1 & $6.5-5.5 \mathrm{kyr}$ & 15 & 107.1 & 4.06 & $(1-2) 0.31$ & .580 & $(1-2) 0.94$ & .926 \\
\hline \multirow[t]{4}{*}{ supraorbital breadth } & 2 & $5.5-4.5 \mathrm{kyr}$ & 13 & 107.0 & 3.34 & $(2-3) 0.53$ & .471 & $(2-3) 0.05$ & .956 \\
\hline & 3 & $4.5-3.5 \mathrm{kyr}$ & 26 & 106.9 & 4.39 & $(3-4) 0.72$ & .398 & $(3-4) 2.94$ & .004 \\
\hline & 4 & $3.5-2.5 \mathrm{kyr}$ & 65 & 104.2 & 3.74 & (4-5) 0.01 & .904 & $(4-5) 2.35$ & .021 \\
\hline & 5 & Modern & 37 & 102.5 & 3.48 & $(1-5) 0.35$ & .556 & $(1-5)-4.17$ & .000 \\
\hline \multirow[t]{5}{*}{ Nasion-prosthion } & 1 & $6.5-5.5 \mathrm{kyr}$ & 14 & 75.7 & 3.96 & $(1-2) 0.04$ & .841 & $(1-2) 0.23$ & .822 \\
\hline & 2 & $5.5-4.5 \mathrm{kyr}$ & 13 & 75.4 & 3.54 & $(2-3) 4.64$ & .038 & $(2-3)-0.13$ & .898 \\
\hline & 3 & $4.5-3.5 \mathrm{kyr}$ & 24 & 75.6 & 6.17 & $(3-4) 6.64$ & .012 & $(3-4) 1.19$ & .239 \\
\hline & 4 & $3.5-2.5 \mathrm{kyr}$ & 55 & 73.9 & 4.28 & (4-5) 0.02 & .872 & 0.21 & .827 \\
\hline & 5 & Modern & 35 & 73.8 & 3.68 & $(1-5) 0.36$ & .548 & $(1-5)-1.63$ & .110 \\
\hline \multirow[t]{5}{*}{ Orbital height } & 1 & $6.5-5.5 \mathrm{kyr}$ & 15 & 32.8 & 2.11 & $(1-2) 0.10$ & .755 & $(1-2)-1.14$ & .264 \\
\hline & 2 & $5.5-4.5 \mathrm{kyr}$ & 13 & 33.8 & 2.73 & $(2-3) 0.21$ & .642 & $(2-3)-0.21$ & .837 \\
\hline & 3 & $4.5-3.5 \mathrm{kyr}$ & 25 & 34.0 & 1.82 & $(3-4) 2.50$ & .117 & (3-4) 0.68 & .494 \\
\hline & 4 & $3.5-2.5 \mathrm{kyr}$ & 66 & 33.6 & 2.39 & (4-5) 1.20 & .275 & $(4-5)-5.70$ & .000 \\
\hline & 5 & Modern & 37 & 36.2 & 1.95 & $(1-5) 0.24$ & .621 & $(1-5) 5.67$ & .000 \\
\hline \multirow[t]{5}{*}{ Orbital breadth } & 1 & $6.5-5.5 \mathrm{kyr}$ & 15 & 41.1 & 2.63 & $(1-2) 0.98$ & .330 & $(1-2) 0.25$ & .806 \\
\hline & 2 & $5.5-4.5 \mathrm{kyr}$ & 13 & 40.7 & 3.67 & $(2-3) 0.76$ & .387 & $(2-3)-0.44$ & .664 \\
\hline & 3 & $4.5-3.5 \mathrm{kyr}$ & 24 & 41.2 & 2.41 & $(3-4) 0.82$ & .368 & $(3-4) 0.64$ & .518 \\
\hline & 4 & $3.5-2.5 \mathrm{kyr}$ & 65 & 40.8 & 2.17 & (4-5) 1.13 & .290 & (4-5) 1.35 & .178 \\
\hline & 5 & Modern & 37 & 40.3 & 1.71 & (1-5) 0.45 & .505 & $(1-5)-1.24$ & .218 \\
\hline
\end{tabular}



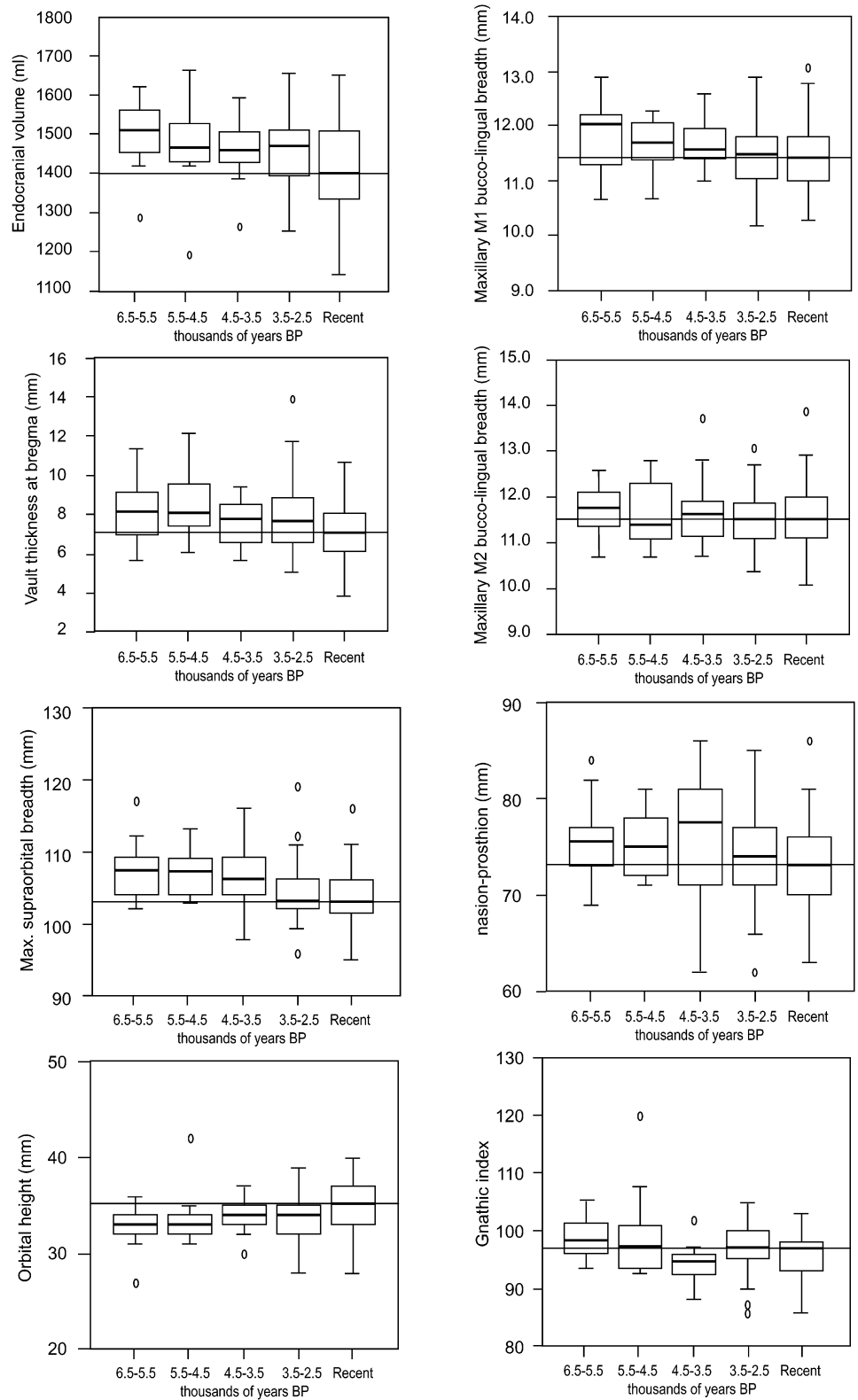

Figure 1. Diachronic change in male cranial and dental dimensions in China.

robusticity (cranial vault thickness and supraorbital breadth) in China. Over the same time period there is a reduction in posterior tooth size, particularly maxillary first molars, with associated loss of alveolar bone and reduction in lower facial prognathism (basion-prosthion). The rate and extent of this change in cranial and facial dimensions is greater after 3,500 years BP, than before. Facial height, prognathism and supraorbital breadth reduce substantially over the last 3,500 years. However, the height of the orbits increases while facial height and prognathism are decreasing (Table 3, Figures 1 and 2). Orbit breadth reduces slightly between the early Neolithic and recent period. Orbital volumes could not be directly measured in the Neolithic crania, as the orbital cavities were often incomplete and remaining sections of orbital plate extremely fragile.

\section{Orbit and facial dimensions in Tohoku Japanese and} Australian Aborigines

Table 4 shows summary statistics for the male and female Tohoku Japanese and Australian Aboriginal samples, with Figure 3 a comparison of average facial proportions in the male Japanese and Aboriginal samples. Male Aborigines have significantly larger orofacial skeletons than females and this is reflected in measures of facial breadth (supraorbital breadth and orbit breadth) and projection (basionnasion and basion-prosthion). Males also have significiantly greater orbital volumes and areas than females, but there is little difference in orbit height. Relative to facial height (nasion-prosthion) female Aborigines have relatively higher orbits than males.

The matrix of sex-based differences is broadly similar in 


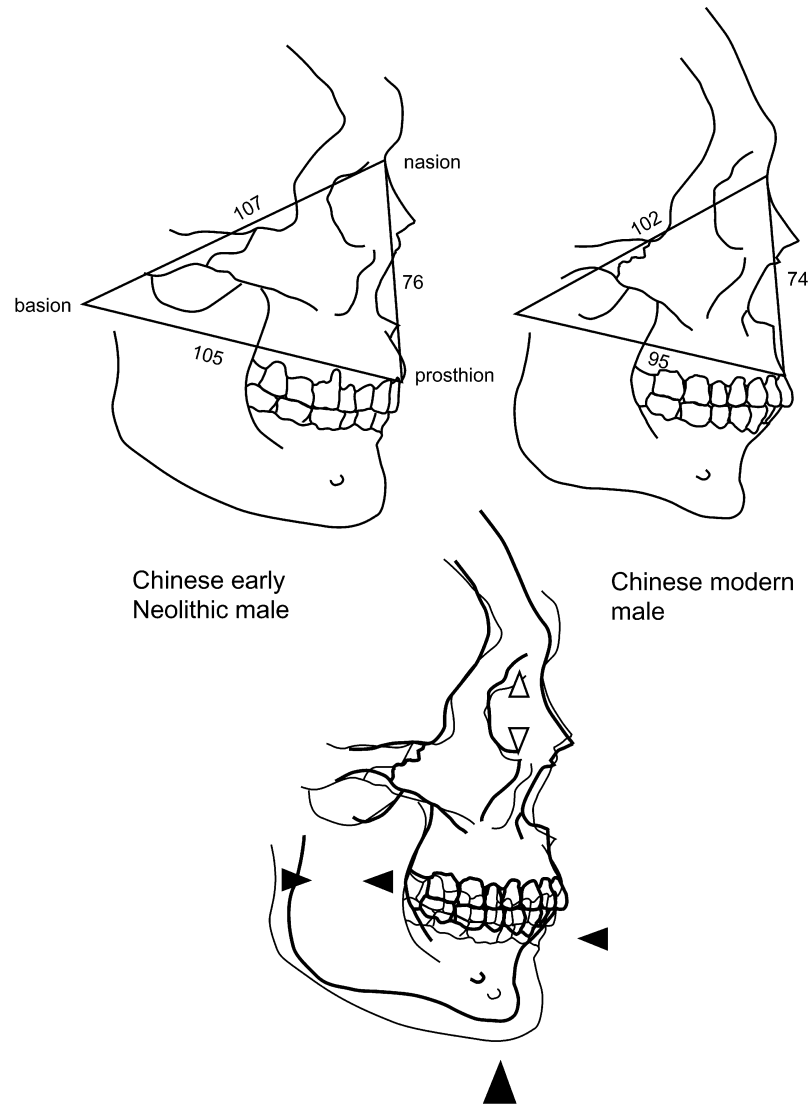

Figure 2. Diachronic change in the average size and shape characteristics of Chinese male facial skeletons, 6,000 BP to modern. Solid arrows indicate areas of facial reduction, hollow arrows expansion.

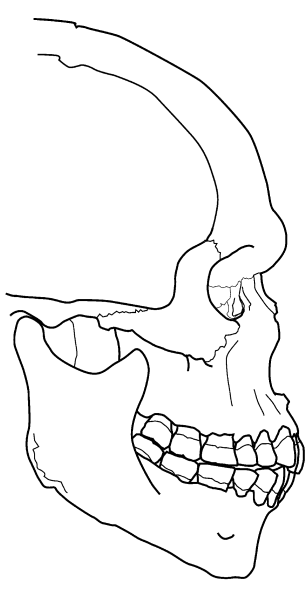

Aust. Aboriginal male average

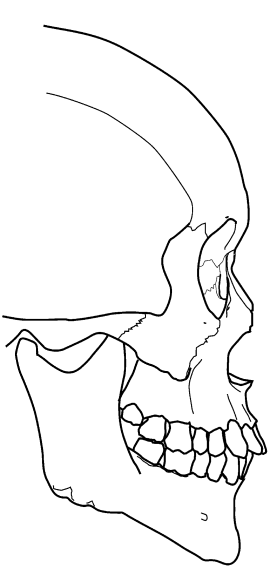

Tohoku Japanese male average
Figure 3. Lateral view of the average size and shape characteristics of the Australian Aboriginal and Tohoku Japanese male facial skeletons used in this study. Note the size of the orbits, the extent of upper facial flatness, posterior tooth size, and lower facial prognathism. Both are to the same scale.

Tohoku Japanese to those in Australian Aborigines. Male Japanese crania have significantly larger orofacial skeletons than females. Facial height (nasion-prosthion), projection (basion-nasion and basion-prosthion), supraorbital breadth and orbital volume are greater in males. Orbit height follows the same pattern seen in Aborigines, with females having relatively high orbits. In contrast to the Aboriginal sample, the differences between the male and female orbit areas are not significant.

Australian Aboriginal male crania have significantly greater orbit volumes, supraorbital breadth and lower facial prognathism (basion-prosthion) than Tohoku Japanese males (Aboriginal male mean gnathic index 101.4, Japanese male mean gnathic index 96.9). While Aboriginal facial skeletons are more prognathic, they are significantly shorter than those in Tohoku Japanese, the latter also having significantly taller orbits. Australian Aboriginal orbits are characterized by relatively great volume and breadth, and reduced height. Mean orbit areas are similar between the male Aboriginal and Japanese samples, with the greater height in Japanese orbits compensating for the reduced breadth.

To a great extent the comparison of Tohoku Japanese and Australian Aboriginal female facial dimensions agrees with that for the males. Australian Aboriginal female crania have significantly greater orbit volumes and facial prognathism (Aboriginal female mean gnathic index 102.6, Japanese female mean gnathic index 99.1) (Table 4, Figure 3). The Australian females have significantly greater supraorbital breadths, and wider orbits, with the Japanese females having taller faces and higher orbits. As in males, orbit area differences are minimal.

\section{Orbit and face relationships in Tohoku Japanese and Australian Aborigines}

The pattern of structural relationships between dimensions of the orbit and face were explored in the individual sexed samples, and the total pooled sample. Table 5 displays the Pearson's correlation matrix for the pooled sample. In all samples orbit volume had high levels of correlation with measures of facial breadth, particularly supraorbital breadth, and projection, but not with facial height. Orbit area has reduced levels of correlation with the same variables, and a stronger association with facial height. In all of the samples orbit height appeared to have no consistent relationship with other facial dimensions, while orbit breadth displayed similar relationships to orbit volume and area. Orbit index (orbital height $\times 100$ /orbital breadth) expresses the relationship of height to breadth, with relatively wide orbits obtaining a lower score. Most of the correlations involving this index are low, and negative, with slightly stronger correlations with facial projection and breadth. This reflects both intra and interpopulation variation, with the broader and more prognathic faces having a generally lower orbit index.

Several facial breadth dimensions, most notably orbital breadth, bi-ectoconchion and supraorbital breadth, cover a closely related anatomical region and this would have inflated the level of correlation between them. Orbital breadth and bi-ectoconchion also share a common lateral point and this would have contributed to their level of correlation. While these three dimensions are closely related measures of upper facial breadth, population based variation in interorbital breadth (bi-lacrimale) increases the complexity of their structural relationship. 
Table 4. Descriptive statistics and significance tests for the Australian Aboriginal and Tohoku Japanese male and female facial dimensions

\begin{tabular}{|c|c|c|c|c|c|c|c|c|}
\hline Dimension & Samples & $\mathrm{N}$ & Mean & s.d. & F (sample pairs) & $P$ & t (sample pairs) & $P$ \\
\hline \multirow[t]{4}{*}{ Orbit volume (ml) } & 1 AAM & 17 & 31.3 & 2.95 & $(1-2) 0.17$ & .682 & $(1-2) 2.83$ & .008 \\
\hline & $2 \mathrm{AAF}$ & 15 & 28.5 & 2.54 & (3-4) 0.52 & .472 & $(3-4) 2.19$ & .034 \\
\hline & 3 TJM & 27 & 24.9 & 2.48 & (1-3) 0.38 & .539 & $(1-3) 7.77$ & .000 \\
\hline & 4 TJF & 17 & 23.2 & 2.17 & $(2-4) 0.63$ & .432 & $(2-4) 6.31$ & .000 \\
\hline \multirow[t]{4}{*}{ Orbit area $\left(\mathrm{mm}^{2}\right)$} & 1 AAM & 19 & 1253.2 & 125.78 & $(1-2) 1.56$ & .219 & $(1-2) 3.02$ & .005 \\
\hline & $2 \mathrm{AAF}$ & 16 & 1140.5 & 86.58 & $(3-4) 4.08$ & .050 & (3-4) 0.53 & .595 \\
\hline & 3 TJM & 27 & 1218.6 & 119.81 & (1-3) 0.01 & .940 & $(1-3) 0.94$ & .350 \\
\hline & 4 TJF & 17 & 1192.8 & 173.81 & $(2-4) 8.73$ & .006 & $(2-4)-1.10$ & .281 \\
\hline \multirow[t]{4}{*}{ Basion-nasion } & 1 AAM & 19 & 103.4 & 3.74 & $(1-2) 0.00$ & .973 & $(1-2) 3.98$ & .000 \\
\hline & $2 \mathrm{AAF}$ & 16 & 98.3 & 3.79 & $(3-4) 4.28$ & .045 & $(3-4) 4.01$ & .000 \\
\hline & 3 TJM & 27 & 101.6 & 4.78 & $(1-3) 1.09$ & .300 & $(1-3) 1.40$ & .168 \\
\hline & 4 TJF & 16 & 96.8 & 2.98 & $(2-4) 1.26$ & .269 & $(2-4) 1.24$ & .223 \\
\hline \multirow[t]{4}{*}{ Basion-prosthion } & 1 AAM & 18 & 104.9 & 4.90 & $(1-2) 0.00$ & .976 & $(1-2) 2.41$ & .022 \\
\hline & $2 \mathrm{AAF}$ & 14 & 100.9 & 4.32 & (3-4) 1.30 & .260 & (3-4) 1.92 & .062 \\
\hline & 3 TJM & 27 & 98.5 & 4.52 & $(1-3) 0.00$ & .973 & $(1-3) 4.46$ & .000 \\
\hline & 4 TJF & 14 & 95.9 & 3.49 & $(2-4) 1.56$ & .222 & $(2-4) 3.36$ & .002 \\
\hline Maximum & 1 AAM & 19 & 110.6 & 4.94 & $(1-2) 2.16$ & .151 & $(1-2) 4.86$ & .000 \\
\hline \multirow[t]{3}{*}{ supraorbital breadth } & $2 \mathrm{AAF}$ & 16 & 103.5 & 3.50 & $(3-4) 0.24$ & .623 & $(3-4) 2.83$ & .007 \\
\hline & 3 TJM & 27 & 102.5 & 4.00 & $(1-3) 0.92$ & .341 & $(1-3) 6.17$ & .000 \\
\hline & $4 \mathrm{TJF}$ & 16 & 99.0 & 3.60 & $(2-4) 0.07$ & .784 & $(2-4) 3.53$ & .001 \\
\hline \multirow[t]{4}{*}{ Nasion-prosthion } & 1 AAM & 18 & 65.1 & 3.43 & $(1-2) 0.59$ & .445 & $(1-2) 1.95$ & .060 \\
\hline & $2 \mathrm{AAF}$ & 14 & 62.5 & 4.27 & (3-4) 0.06 & .799 & $(3-4) 2.05$ & .046 \\
\hline & 3 TJM & 27 & 68.0 & 4.03 & $(1-3) 0.11$ & .741 & $(1-3)-2.50$ & .016 \\
\hline & 4 TJF & 14 & 65.3 & 3.95 & $(2-4) 0.03$ & .860 & $(2-4)-1.83$ & .078 \\
\hline \multirow[t]{4}{*}{ Orbit height } & 1 AAM & 19 & 31.8 & 2.41 & $(1-2) 0.26$ & .612 & $(1-2)-0.20$ & .840 \\
\hline & $2 \mathrm{AAF}$ & 16 & 32.0 & 2.12 & 0.09 & .764 & $(3-4) 0.61$ & .542 \\
\hline & 3 TJM & 27 & 34.1 & 2.03 & (1-3) 0.54 & .466 & $(1-3)-3.50$ & .001 \\
\hline & 4 TJF & 16 & 33.7 & 2.08 & $(2-4) 0.02$ & .886 & $(2-4)-2.35$ & .025 \\
\hline \multirow[t]{4}{*}{ Orbit breadth } & 1 AAM & 19 & 42.9 & 2.19 & $(1-2) 1.36$ & .252 & $(1-2) 2.29$ & .028 \\
\hline & $2 \mathrm{AAF}$ & 16 & 41.3 & 1.78 & $(3-4) 2.83$ & .100 & $(3-4) 1.06$ & .293 \\
\hline & 3 TJM & 27 & 40.7 & 1.81 & $(1-3) 1.67$ & .202 & $(1-3) 3.72$ & .001 \\
\hline & $4 \mathrm{TJF}$ & 16 & 40.0 & 2.75 & $(2-4) 2.07$ & .160 & $(2-4) 1.67$ & .104 \\
\hline
\end{tabular}

Scatter plots were used to determine whether correlations were inflated by the separation of group means, or if there were consistent patterns of population-wide covariation (Figures 4 to 9). Orbit height displayed consistently low levels of correlation with the other facial dimensions, no covariation, high levels of variation, and a generally orthogonal relationship with other facial dimensions (Table 5, Figure 4). Predictably, orbit breadth had a relatively linear relationship with the other measures of upper facial breadth, but the high levels of correlation with facial projection was primarily due to the separation of group centroids. In Figure 5, if the subadults are ignored, there is little evidence of covariation within individual adult samples. The same can be said for orbit area. While there are moderate correlations with a variety of facial dimensions, there is no real covariation (Table 5, Figure 6).

The results for orbit volume contrast with those involving the other orbit dimensions (Table 5, Figures 7 and 8). Supraorbital breadth and lower facial prognathism have a strong structural relationship with orbital volume, with consistently high patterns of covariation. This is particularly true for supraorbital breadth where there is minimal dispersion and a low standard error. The more projecting the facial skeleton, and broader the supraorbital region, the greater the orbital volume. There is also a broad association between orbit volume and the shape of the orbit as reflected by the

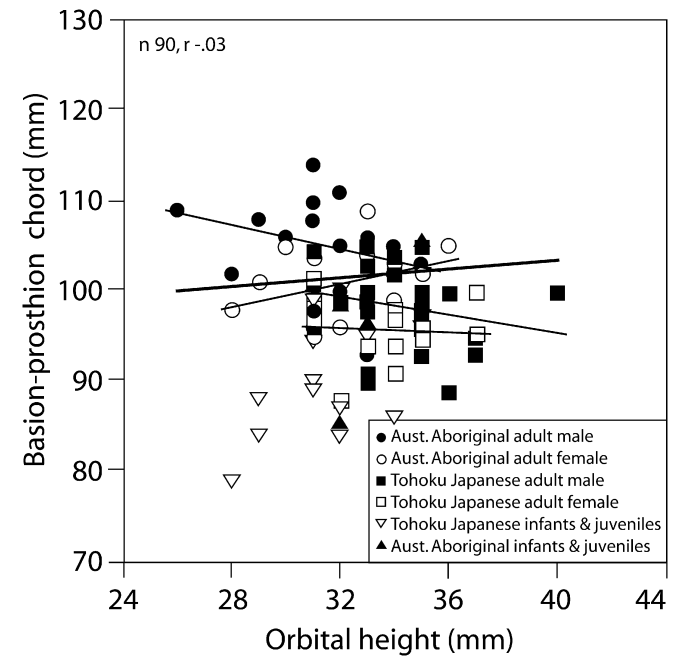

Figure 4. Scatterplot of the relationship between basion-prosthion chord $(\mathrm{mm})$ and orbital height $(\mathrm{mm})$ in Australian Aboriginal and Tohoku Japanese crania. In order to visualize levels of covariation, regression lines for the pooled sample, as well as individual adult samples, are plotted. 


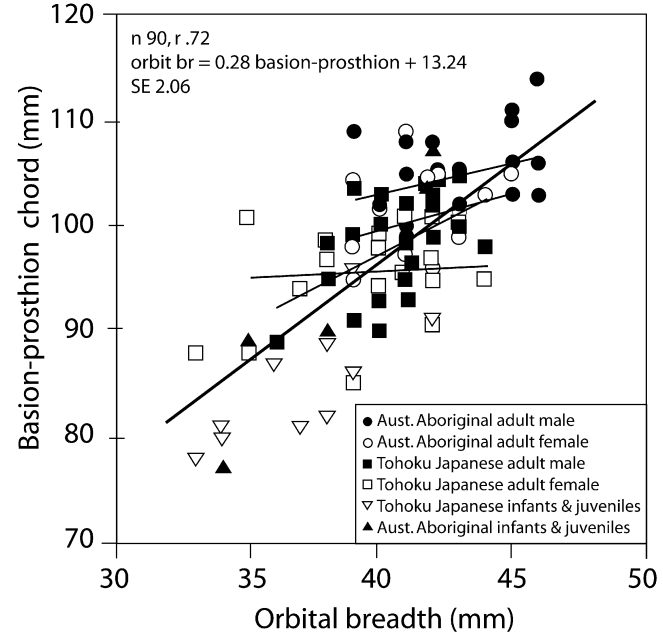

Figure 5. Scatterplot of the relationship between basion-prosthion chord $(\mathrm{mm})$ and orbital breadth $(\mathrm{mm})$ in Australian Aboriginal and Tohoku Japanese crania.

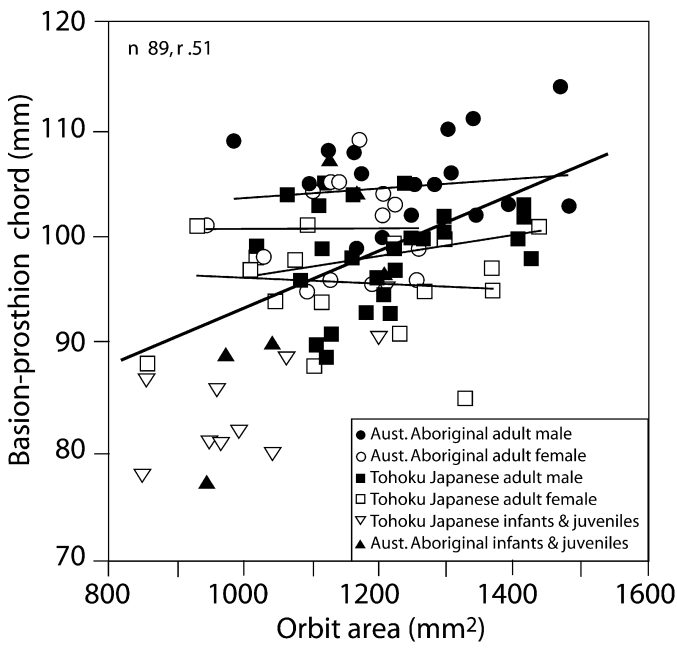

Figure 6. Scatterplot of the relationship between basion-prosthion chord $(\mathrm{mm})$ and orbit area $\left(\mathrm{mm}^{2}\right)$ in Australian Aboriginal and Tohoku Japanese crania.

orbital index (Figure 9). Orbits with relatively great height tend to have lower volumes than orbits which are lower, and more rectangular in shape.

\section{Estimation of orbit volumes in the Chinese Neolithic samples}

Poor preservation prevented direct measurement of orbital volumes in the Chinese Neolithic samples. In order to estimate these volumes, a standard multiple regression was performed with the pooled Australian Aboriginal and Tohoku Japanese data sets with orbit volume as the dependent variable and basion-prosthion, supraorbital breadth, and infraorbital breadth as independent variables. Presence of outliers, normality, linearity, and homoscedasticity of residuals were evaluated. With the use of a $p<.001$ criterion for Mahalanobis distance no outliers among the cases were found. Table 6 displays the correlations between the vari-

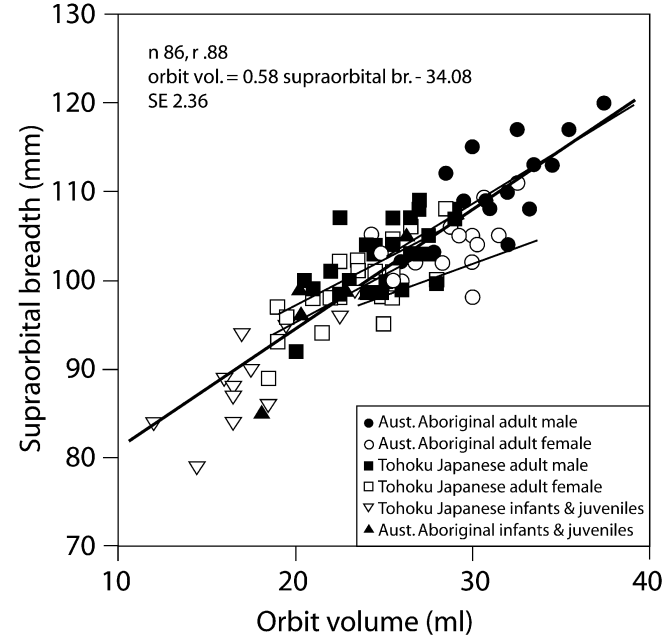

Figure 7. Scatterplot of the relationship between maximum supraorbital breadth $(\mathrm{mm})$ and the volume of the right orbit $(\mathrm{ml})$ in Australian Aboriginal and Tohoku Japanese crania.

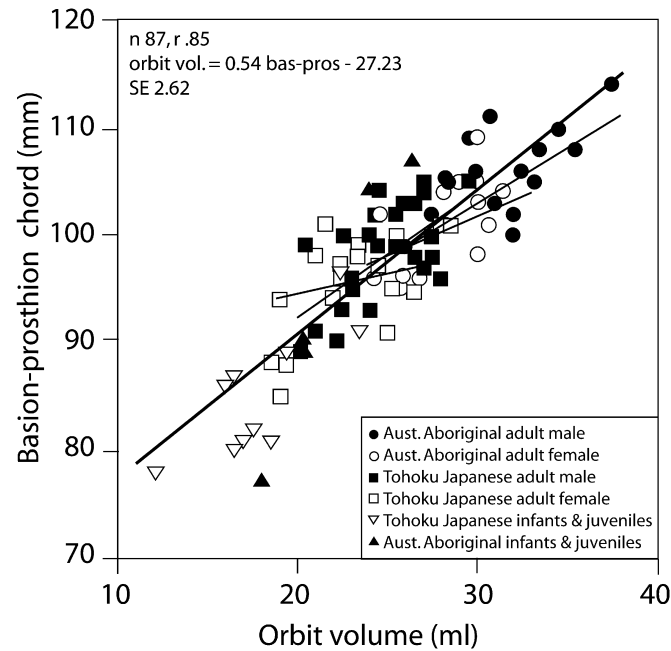

Figure 8. Scatterplot of the relationship between basion-prosthion chord $(\mathrm{mm})$ and orbit volume $(\mathrm{ml})$ in Australian Aboriginal and Tohoku Japanese crania.

ables, the unstandardized regression coefficients (B) and intercept, the standardized regression coefficients $(\beta), R^{2}$, and adjusted $\mathrm{R}^{2}$. $\mathrm{R}$ for regression was significantly different from zero, $\mathrm{F}(3,83)=165.54, p<.001$. All three coefficients differed significantly from zero, and all IV's contributed significantly to the prediction of orbit volume. The confidence limits for basion-prosthion were 0.126 to 0.316 , supraorbital breadth 0.419 to 0.635 , and infraorbital breadth -0.721 to 0.219 .

The prediction equation (orbit volume $=-37.418+0.221$ basion-prosthion+0.527 supraorbital br. -0.524 infraorbital br.) was then used to estimate the orbit volumes in 20 Tohoku Japanese crania, with known orbit volumes, which had not been part of the original sample. Known volumes and estimated volumes were compared using paired t-tests and Pearson's correlation coefficient (Table 7). Sample 


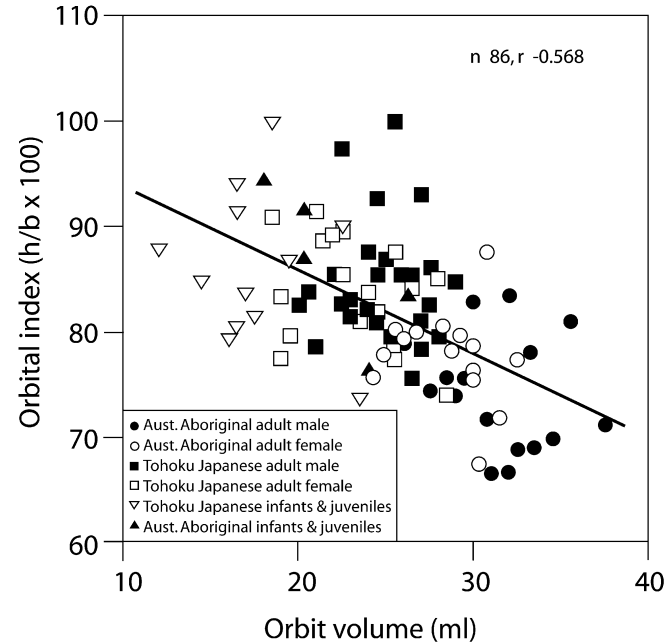

Figure 9. Scatterplot of the relationship between orbital index and the volume of the right orbit (ml) in Australian Aboriginal and Tohoku Japanese crania.

Table 5. Pearson's $r$ correlation matrix for orbital and facial dimensions in the pooled Tohoku Japanese and Australian Aboriginal sample $(\mathrm{n}=86)$

\begin{tabular}{lrrrrr}
\hline \multicolumn{1}{c}{ Variable list } & $\begin{array}{c}\text { Orbit } \\
\text { volume }\end{array}$ & $\begin{array}{c}\text { Orbit } \\
\text { area }\end{array}$ & $\begin{array}{c}\text { Orbit } \\
\text { height }\end{array}$ & $\begin{array}{c}\text { Orbit } \\
\text { breadth }\end{array}$ & $\begin{array}{c}\text { Orbit } \\
\text { index }\end{array}$ \\
\hline Orbit area & 0.57 & & & & \\
Orbit height & -0.09 & 0.46 & & & \\
Orbit breadth & 0.76 & 0.73 & 0.24 & & \\
Orbit index & -0.55 & -0.38 & 0.14 & -0.48 & \\
Basion-nasion & 0.73 & 0.64 & 0.15 & 0.74 & -0.29 \\
Basion-nasospinale & 0.83 & 0.54 & -0.01 & 0.74 & -0.38 \\
Basion-prosthion & 0.85 & 0.51 & -0.03 & 0.74 & -0.44 \\
Supraorbital breadth & 0.88 & 0.63 & -0.00 & 0.82 & -0.47 \\
Bi-zygion & 0.72 & 0.63 & 0.14 & 0.71 & -0.35 \\
Nasion-nasospinale & 0.49 & 0.61 & 0.44 & 0.63 & -0.36 \\
Nasion-prosthion & 0.43 & 0.61 & 0.48 & 0.61 & -0.25 \\
Nasospinale-prosthion & 0.17 & 0.36 & 0.32 & 0.35 & 0.00 \\
Nasal breadth & 0.59 & 0.33 & -0.02 & 0.55 & -0.39 \\
Infraorbital breadth & 0.40 & 0.50 & 0.26 & 0.56 & -0.14 \\
Bi-FMO & 0.85 & 0.67 & 0.07 & 0.87 & -0.46 \\
\hline
\end{tabular}

Table 6. Standard multiple regression of basion-prosthion, supraorbital breadth and infraorbital breadth on orbit volume

\begin{tabular}{|c|c|c|c|c|c|c|c|}
\hline & $\begin{array}{c}\text { Orbit } \\
\text { volume } \\
\text { (DV) }\end{array}$ & $\begin{array}{l}\text { Basion- } \\
\text { prosthion }\end{array}$ & $\begin{array}{l}\text { Supra- } \\
\text { orbital }\end{array}$ & $\begin{array}{l}\text { Infra- } \\
\text { orbital }\end{array}$ & & & \\
\hline mean & 25.3 & 97.8 & 101.8 & 23.9 & & & \\
\hline s.d. & 4.91 & 7.68 & 7.34 & 2.75 & & & \\
\hline Pearson's r & & & & & $\mathrm{B}$ & $\beta$ & $\begin{array}{c}\mathrm{sr}^{2} \\
\text { (unique) }\end{array}$ \\
\hline Basion-pros. & .83 & & & & 0.221 & 0.34 & 0.04 \\
\hline Supraorbital & .88 & .83 & & & 0.527 & 0.79 & 0.16 \\
\hline Infraorbital & .42 & .58 & .66 & & -0.524 & -0.29 & 0.05 \\
\hline & & & & \multicolumn{4}{|c|}{ Intercept $=-37.418$} \\
\hline
\end{tabular}

$\mathrm{R}^{2}=.86^{*}$, adjusted $\mathrm{R}^{2}=.85, \mathrm{R}=.92, p<.001$, *unique variability $=0.07$, shared variability $=0.79$
Table 7. Comparison of known orbit volumes with estimated orbit volumes in 20 Tohoku Japanese crania

\begin{tabular}{lccccccc}
\hline N=20 & $\begin{array}{c}\text { Known } \\
\text { volume }\end{array}$ & $\begin{array}{c}\text { Estimated } \\
\text { volume }\end{array}$ & $\begin{array}{c}\text { Volume } \\
\text { difference }\end{array}$ & $\mathrm{t}$ & $P$ & $\mathrm{r}$ & $P$ \\
\hline mean & 24.3 & 24.6 & 1.76 & -0.78 & 0.444 & 0.70 & 0.001 \\
s.d. & 2.97 & 2.01 & 1.17 & & & & \\
\hline
\end{tabular}

Paired t-test and Pearson's correlation coefficient.

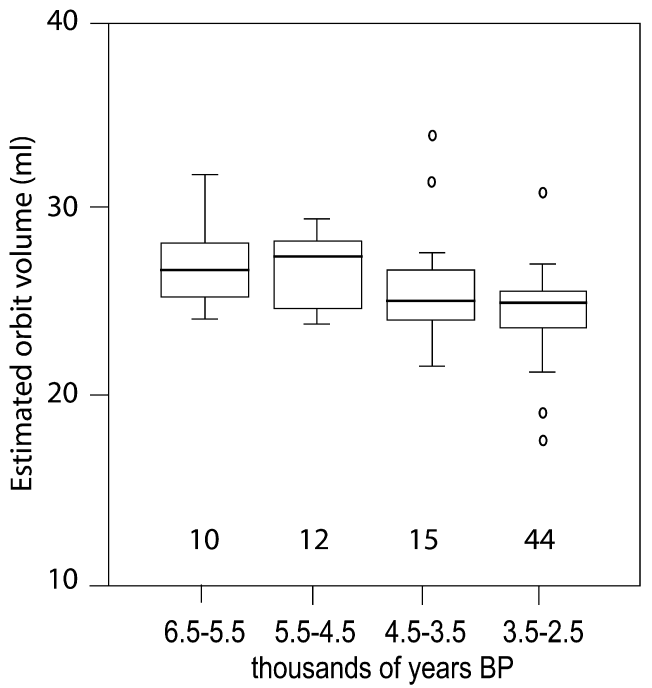

Figure 10. Box plots of diachronic change in predicted male orbit volume between 6,500 and 2,500 years BP in China.

means were similar, differences between the means not significant, and there was a significant correlation between known and estimated volumes. Scatterplots, and examination of the raw data, indicated that errors in estimation were greatest with large orbit volumes.

The multiple regression equation was then used to estimate orbit volume in the four Chinese Neolithic samples using basion-prosthion, supraorbital breadth, and infraorbital breadth as the independent variables (Figure 10). These results suggest a gradual decline in orbit volume through the Neolithic, with a similar diachronic trend to that recorded for endocranial volume, facial breadth and prognathism and posterior tooth size, Fig 1. As the volume of the orbit decreased there was a corresponding increase in orbit height.

\section{Discussion}

\section{Post-Pleistocene diachronic change in China}

The evidence for post-Pleistocene diachronic change in human cranial and oro-facial dimensions in China, which we describe, follows a similar pattern to that previously recorded for north Africa and the Levant, and Australia (Carlson, 1976; Carlson and Van Gervan, 1977; Smith et al., 1985, 1986; Calcagno, 1986; Brown, 1987, 1992a; Henneberg and Steyn, 1993). Endocranial volumes decrease, cranial superstructures become less robust, and there is a reduction in lower facial prognathism, facial height, supraorbital breadth and posterior tooth size. 
Preferential preservation and ease of measurement have resulted in most of the previous studies of post-Pleistocene change concentrating on tooth size (Bailit and Friedlaender, 1966; Brace and Mahler, 1971; Brose and Wolpoff, 1971; Le Blanc and Black, 1974; Frayer, 1977; Calcagno, 1986; Macchiarelli and Bondioli, 1986; Smith et al., 1986; Brace et al., 1987; Formicola, 1987). Where samples are sexed, and dimensions unaffected by wear are recorded, the evidence for directional reduction in posterior tooth size after 10,000 years BP is clear. In this study posterior dental reduction is most evident before 3,500 BP, with no significant change in the last 2000 years. This contrasts with other indicators of body size (endocranial volume) and facial size and robusticity which indicate substantial reduction after 2000 years BP.

Explanations of post-Pleistocene diachronic change in human cranio-facial size and morphology and tooth dimensions usually emphasize the impact of some aspect of the Neolithic transition. For directional change in tooth size it is often claimed that the improvement in food preparation technologies and the use of softer and less abrasive carbohydrate staples reduced the selective pressures for large, slow wearing teeth (Brace and Mahler, 1971; Le Blanc and Black, 1974; Brace, 1978; y'Edynak, 1978; Kennedy, 1984). Why this might result in tooth size reduction is not clear, as the selective advantages of smaller teeth, or disadvantages of maintaining larger teeth without an impact on reproductive fitness, are never stated. Alternatively, tooth size reduction could be the allometric byproduct of reduction in body size. Something like an extended version of the modern secular growth trend, but set in reverse (Tanner, 1981). Under this model, the sedentary village lifestyles, higher population densities, and potentially greater competition for resources may have favored the reproductive success of smaller bodied individuals (Frisancho et al., 1973; Macchiarelli and Bondioli, 1986).

Cross cultural comparisons of post-Pleistocene change in facial and dental proportions highlight problems with the existing explanatory models. In Australia the founding population were hunter-gatherer's, with an essentially Mesolithic level of technology (Mulvaney and Kamminga, 1999). Both at European contact and at the end of the Pleistocene the first Australians were characterized by extremely high levels of tooth wear. Selection for a large and robust masticatory system seems to have been maintained over the $>40,000$ years in which Australia was occupied, and there is little evidence of gene flow from smaller toothed populations in south-east Asia. However, between 12,000 and 4,000 years BP there is significant reduction in tooth size, and the size, prognathism and robusticity of the orofacial skeleton (Brown, 1989, 1992a, b). At the same time population densities remain relatively low, permanent villages and agriculture are not present, and premasticatory preparation of food is minimal. It is unlikely that diachronic change in Australian Aboriginal facial skeletons was a response to the relaxation of selection for large teeth, or selection favoring smaller body size due to competition for resources.

It also appears that the prevailing anthropological explanations for the post-Pleistocene diachronic trend for reduction in tooth size, and change in oro-facial dimensions, do not work particularly well for China. Millet based agricul- ture, use of pottery cooking vessels, and village lifestyles were present in the Chinese river valleys by 7,000 BP (Yan, 1992; Liu, 1996). Through the Yangshao and Longshan archaeological data suggest a decreased reliance on nondomesticated food resources and increasing population densities, which continued into the Dynastic periods. However, while there is a significant reduction in posterior tooth size, levels of tooth wear remain high and do not indicate any relaxation of the selection for slower wearing teeth (Pechenkina et al., 2002; PB personal observation). In northeastern China it is more likely that the reduction in body size, cranial dimensions and tooth size is linked to either retarded growth, or selection for smaller body size, which is reflected in the deterioration in community health towards the end of the Longshan period, around 4,000 BP (Pechenkina et al., 2002).

\section{The orbits}

In China while there is a reduction in facial height, prognathism of the lower face and supraorbital breadth through the Neolithic period, there is a relative and absolute increase in the height of the orbits. This increase in orbit height is consistent with the pattern of post-Pleistocene change in other parts of the world where trends in facial size and shape over this time period have been examined (Carlson, 1976; Brown, 1989, 1992b). The functional associations of orbit size, shape and volume were examined in two groups of modern human crania, with contrasting cranial vault and oro-facial morphologies. These two groups, Tohoku Japanese and Australian Aborigines, were chosen as to some extent they mirrored the differences between early Neolithic and modern Chinese populations. The Australian sample was characterized by a dolichocranic cranial vault, broad and robust supraorbital region, prognathic lower face and low, rectangular orbits; the Tohoku Japanese by a brachycranic cranial vault, minimal facial prognathism, and high, rounded orbits.

Consistent patterns of sexual dimorphism in facial dimensions, and orbit height, breadth, area and volume were found in the Australian Aboriginal and Tohoku Japanese samples. While male orbital and facial dimensions are generally significantly larger than those in females, relative to the size of the facial skeleton female orbits are slightly larger. The low and rectangular orbits in the Australian samples were associated with significantly greater orbital volumes than in the Japanese samples. The individual, and pooled, modern samples were used to examine the functional relationships between dimensions of the orbit, other parts of the facial skeleton, and cranial base. Bivariate correlation, scatterplots and multiple regression results indicated that orbit volume could be predicted from a combination of supraorbital breadth, infraorbital breadth and lower facial prognathism. Orbital height displayed little covariation with other facial dimensions, partly due to relatively tall orbits in the smaller female orofacial skeletons. The regression equation developed to predict orbit volume was tested on an independent Tohoku Japanese sample and then applied to the Neolithic Chinese crania. While orbit heights are increasing through the Chinese Neolithic, orbit volumes are decreasing.

Human orbits are complex structures, with seven bones 
forming the walls of the somewhat pear-shaped twin cavities, where the stalk end represents the optic canal (Warwick, 1976). The primary role of the orbits is to protect the eyes, provide attachment for the muscles controlling eye movement, and help support the frontal lobes of the brain. Principal contents of the orbits include the eyeballs, extraocular muscles, orbital fat, nerves and blood supply, and lacrimal glands. Variation is evident in the size and morphology of the orbital apertures, as well as in the shape of the cavities, the foramina and grooves within them, and the individual bones of which the orbits are comprised (Adachi, 1904b; Pan, 1933; Woo, 1937-38; Schultz, 1940; Ray, 1955; Riesenfeld, 1956; Kier, 1966; Post, 1969; Ossenberg, 1970; Warwick, 1976)

The growth of the eyes follows the rapid pattern of neural growth, although slower than the brain, and this is reflected in the relatively large size of the orbits in infants and children (Todd et al., 1940; Moore and Lavelle, 1974). Up until the expansion of the maxilla which accompanies the development of the permanent dentition, the orbits dominate the facial skeleton. Most of the increase in facial height during later growth is suborbital, with orbital height showing relative stability. Orbital breadth increases with the growth of the supraorbital region, and the increase in interorbital width due to the expansion of the ethmoidal air cells. In humans, unlike the reasonably close association between the contours and volume of the brain and the endocranial surface, the eyeball only occupies approximately 32 percent of orbit volume in adulthood (Schultz, 1940; Warwick, 1976), and eyeball size does not appear to be correlated with either endocranial volume or body size (Todd et al., 1940). Most of the remaining orbital volume is filled by the recti muscles and orbital fat. If orbital volumes are large, with a long antero-posterior axis to the orbit and great supraorbital breadth, it is possible for the eyeballs to be relatively deeply set.

Where crania have a shorter cranial base, in association with a less projecting lower face and reduced upper facial breadth, orbit volumes are reduced. This would decrease the volume available for the recti muscles, and orbital nerves and blood vessels, pushing the eyeball into a more anterior or relatively protruding position. A situation analogous to this in the degree of protrusion of the eye, and extent of facial flatness, occurs in domestic breeds of dog. While there is only limited comparative evidence to support this view in humans, Adachi (1904a) suggested that this was the situation in modern Japanese when compared with other modern human populations with more projecting facial skeletons (Adachi, 1904a, b). This is in marked contrast with fossil hominids like Arago 21 (right orbit volume $44 \mathrm{ml}$, measured from a cast) and Kabwe (right orbit volume $46 \mathrm{ml}$ ) whose supraorbital development, facial projection and orbit volumes exceed the modern human range of variation (modern human adult orbit volume range is $18-38 \mathrm{ml}$ ).

\section{Conclusions}

The associations between dimensions of the orbit, facial skeleton and neurocranium were examined in morphologically contrasting modern human samples, Tohoku Japanese and Australian Aborigines. While some orbital dimensions display consistent patterns of covariation with craniofacial dimensions, others do not. In the Australian and Japanese samples orbit volumes could be predicted with regression equations based on dimensions of upper facial breadth and facial prognathism. Applying these equations to Neolithic populations in China indicates that orbital volumes decrease between 6,000 and 3,000 years BP, while orbital height is increasing and facial height decreasing. Reducing facial prognathism, supraorbital breadth and a shorter, more brachycranic, cranial vault reduce the length and breadth of the orbital cavity. If the volume of the orbit is reduced the contents of the orbit might be forced into a more anterior position. While the correlations between orbit volume and size of the eyeball are low (Schultz, 1940; Todd et al., 1940; Warwick, 1976), the correlations between the total contents of the orbit and orbit volume would be high as the orbits are usually full. If it is the total volume occupied by the eyeball, extraocular muscles, nerves and blood supply which are important, rather than just the size of the eyeball, then there would need to be some functional compensation for any significant reduction in orbit length and volume. While this requires further research, it is possible that the tendency for orbit heights to increase, when orbit volumes decrease, reflect an expansion of the anterior third of the orbit for a repositioned eyeball and associated musculature.

\section{Acknowledgements}

For access to skeletal materials in their care PB would like to thank Professor Han Kangxin and Zhang Yajun, Institute of Archaeology, Academy of Social Sciences, Beijing; Professor's Wu Rukang, Wu Xinzhi, and Zhang Yinyun, Institute of Vertebrate Paleontology and Paleoanthropology, Academia Sinica, Beijing; Professor Chris Stringer and Robert Kruszynski, Natural History Museum, London, and Professor Yukio Dodo, Tohoku University School of Medicine. Phoebe Newman provided assistance while collecting data in China. This research was completed while PB was visiting Research Professor in the Department of Anatomy and Anthropology, Tohoku University School of Medicine. $\mathrm{He}$ is extremely grateful to Yukio Dodo, and the staff and students of the Department for the help and friendship they provided while in Japan. PB and TM would also like to thank Dr. Yuji Mizoguchi, National Science Museum, Tokyo, for encouragement and organisation of the session at the International Congress where this paper was presented, and the two anonymous reviewers of the original manuscript.

\section{References}

Adachi B. (1904a) Die Orbita und die Hauptmasse des Schädels der Japaner und die Methode der Orbitalmessung. Zeitschrift fuer Morphologie und Anthropologie, 7: 379-480.

Adachi B. (1904b) Topographische Lage des Augapfels der Japaner. Zeitschrift fuer Morphologie und Anthropologie, 7: 481501.

Bailit H.L. and Friedlaender J.S. (1966) Tooth size reduction: a Hominid trend. American Anthropologist, 68: 665-672.

Bass W.M. (1971) Human Osteology: A Laboratory and Field Manual of the Human Skeleton. Missouri Archaeological 
Society, Columbia.

Brace C.L. (1978) Tooth reduction in the Orient. Asian Perspectives, 19: 203-219.

Brace C.L. and Mahler P.E. (1971) Post-Pleistocene changes in the human dentition. American Journal of Physical Anthropology, 34: 191-204.

Brace C.L., Shae X-Q., and Zhang Z-B. (1984) Prehistoric and modern tooth size in China. In: Smith F.H. and Spencer F. (eds.) "The Origins of Modern Humans," Alan R. Liss, New York, pp. 485-516.

Brace C.L., Rosenberg K.R., and Hunt K.D. (1987) Gradual change in human tooth size in the late Pleistocene and postPleistocene. Evolution, 41: 705-720.

Brose D.S. and Wolpoff M.H. (1971) Early Upper Paleolithic man and late Middle Paleolithic tools. American Anthropologist. 73: 1156-1194.

Brown P. (1987) Pleistocene homogeneity and Holocene size reduction: the Australian human skeletal evidence. Archaeology in Oceania, 22: 41-71.

Brown P. (1989) Coobool Creek: a morphological and metrical analysis of the crania, mandibles and dentitions of a prehistoric Australian human population. Terra Australis 13, Department of Prehistory, Australian National University, Canberra

Brown P. (1992a) Post-Pleistocene change in Australian Aboriginal tooth size: dental reduction or relative expansion? In: Brown T. and Molnar S. (eds.) "Human Craniofacial Variation in Pacific Populations," Anthropology and Genetics Laboratory, University of Adelaide, pp. 33-52.

Brown P. (1992b) Recent human evolution in East Asia and Australasia. Philosophical Transactions of the Royal Society of London, Series B 337: 235-242.

Brown P. (1998-2003) Australian and Asian Palaeoanthropology. http://metz.une.edu.au/ pbrown3/palaeo.html

Calcagno J.M. (1986) Dental reduction in post-Pleistocene Nubia. American Journal of Physical Anthropology, 70: 349-363.

Calcagno J.M. and Gibson K.R. (1988) Human dental reduction: natural selection or the probable mutation effect. American Journal of Physical Anthropology, 77: 505-517.

Carlson D.S. (1976) Temporal variation in prehistoric Nubian crania. American Journal of Physical Anthropology, 45: 467484.

Carlson D.S. and Van Gervan D.P. (1977) Masticatory function and post-Pleistocene evolution in Nubia. American Journal of Physical Anthropology, 46: 495-506.

Christensen A.F. (1998) Odontometric microevolution in the Valley of Oaxaca, Mexico. Journal of Human Evolution, 34: $333-$ 360.

Formicola V. (1987) Neolithic transition and dental changes: the case of an Italian site. Journal of Human Evolution, 16: 231240.

Frayer D.W. (1977) Metric dental changes in the European Upper Paleolithic and Mesolithic. American Journal of Physical Anthropology, 46: 109-120.

Frayer D.W (1978) The evolution of the dentition in Upper Paleolithic and Mesolithic Europe. Monographs in Anthropology, No. 10, University of Kansas.

Frisancho A.R., Sanchez J., Pallardel D., and Yanez L. (1973) Adaptive significance of small body size under poor socioeconomic conditions in southern Peru. American Journal of Physical Anthropology, 39: 255-262.

Henneberg M. and Steyn M. (1993) Trends in cranial capacity and cranial index in Subsaharan Africa during the holocene. American Journal of Human Biology, 5: 473-479.

Jacobs K. (1994) Human dento-gnathic metric variation in Mesolithic/Neolithic Ukraine-possible evidence of demic diffusion in the Dnieper Rapids region. American Journal of Physical Anthropology, 95: 1-26.

Kennedy K.A.R. (1984) Biological adaptations and affinities of
Mesolithic South Asians. In: Lukacs J.R. (ed.) "The People of South Asia," Plenum Press, New York, pp. 29-58.

Kier E.L. (1966) Embryology of the normal optic canal and its anomolies. Investigative Radiology, 1: 346-362.

Le Blanc S.A. and Black B. (1974) A long term trend in tooth size in the eastern Mediterranean. American Journal of Physical Anthropology, 41: 417-422.

Liu L. (1996) Settlement patterns, chiefdom variability, and the development of early states in North China. Journal of Anthropological Archaeology, 15: 237-288.

Lukacs J.R. (1984) Dental anthropology of South Asian populations. In: JR Lukacs (ed.): "The People of South Asia," Plenum Press, New York, pp. 133-158.

Macchiarelli R. and Bondioli L. (1986) Post-Pleistocene reductions in human dental structure: a reappraisal in terms of increasing population density. Human Evolution, 1: 405-418.

Martin R. and Saller K. (1957) Lehrbuch der Anthropologie. Gustav Fischer Verlag, Stuttgart.

Moore W.J. and Lavelle C.L.B. (1974) Growth of the Facial Skeleton in the Hominoidea. Academic Press, London.

Mulvaney J. and Kamminga J. (1999) Prehistory of Australia. Allen and Unwin, Sydney.

Ossenberg N.S. (1970) The influence of artificial cranial deformation on discontinuous morphological traits. American Journal of Physical Anthropology, 33: 357-372.

Pan T.H. (1933) Measurement of the Chinese orbit. Journal of Anatomy, 67: 596-598.

Pechenkina E.A., Benfer R.A., and Wang Z. (2002) Diet and health changes at the end of the Chinese Neolithic: the Yangshao/ Longshan transition in Shaanxi Province. American Journal of Physical Anthropology, 117: 15-36.

Post R.H. (1969) Tear duct size differences of age, sex and race. American Journal of Physical Anthropology, 30: 85-88.

Ray C.D. (1955) Configuration and lateral closure of the superior orbital fissure. American Journal of Physical Anthropology, 13: 309-321.

Riesenfeld A. (1956) Multiple infraorbital, ethmoidal and mental foramina in the races of man. American Journal of Physical Anthropology, 14: 85-100.

Schultz A.H. (1940) The size of the orbit and of the eye in primates. American Journal of Physical Anthropology, 26: 389408.

Smith P., Bloom R.A., and Berkovitz J. (1984) Diachronic trends in humeral cortical thickness. Journal of Human Evolution, 13: 603-611.

Smith P., Wax Y., Becher A., and Einy S. (1985) Diachronic variation in cranial thickness. American Journal of Physical Anthropology, 67: 127-133.

Smith P., Wax Y., Adler F, Silberman D., and Heinic G. (1986) Post-Pleistocene changes in tooth root and jaw relationships. American Journal of Physical Anthropology, 70: 339-348.

Sofaer J.A. (1973) A model relating developmental interaction and differential evolutionary reduction of tooth size. Evolution, 27: 427-434.

Sofaer J.A., Bailit H.L., and MacLean C.J. (1971) A developmental basis for differential tooth reduction during hominid evolution. Evolution, 25: 509-517.

SPSS (1990) SPSS Reference Guide. SPSS Inc, Chicago.

Systat (2002) SYSTAT 10.2. Systat Software Inc, Richmond.

Tanner J.M. (1981) A History of the Study of Human Growth. Cambridge University Press, Cambridge.

Todd T.W., Beecher H., Williams G.H., and Todd A.W. (1940) The weight and growth of the human eyeball. Human Biology, 12: $1-20$

Warwick R. (1976) Eugene Wolf's Anatomy of the Eye and Orbit. H.K. Lewis and Co. Ltd, London.

Woo T.L. (1937-38) A biometric study of the human malar bone. Biometrica, 29: 113-123.

Yan W. (1992) Origins of agriculture and animal husbandry in 
China. In: Aikens C.M. and Rhee S.N. (eds.) "Pacific Northeast Asia in Prehistory," Washington State University Press, Pullman, pp. 113-123.

y'Edynak G. (1978) Culture, diet, and dental reduction in
Mesolithic forager-fishers of Yugoslavia. Current Anthropology, 19: 616-618.

y’Edynak G. (1989) Yugoslav Mesolithic dental reduction. American Journal of Physical Anthropology, 78: 17-36. 